\title{
COMPLETE DISTRIBUTION PATTERNS OF NEURONS WITH CHARACTERISTIC ANTIGENS IN THE LEECH CENTRAL NERVOUS SYSTEM $^{1}$
}

\author{
BIRGIT ZIPSER ${ }^{2}$
}

\author{
Cold Spring Harbor Laboratory, Cold Spring Harbor, New York 11724
}

Received February 16, 1982; Revised May 6, 1982; Accepted May 6, 1982

\begin{abstract}
Monoclonal antibodies were used to map the distribution of neurons in the leech which contain a particular antigen. This technique reveals the genetically determined variation in cell body distribution along the nerve cord. In addition, antibodies also reveal developmental deviations, such as the occurrence of supernumerary cell bodies. Three antibodies that bind either to single types or small sets of different neurons are used to construct complete distribution patterns of antigenically related cells. Three other antibodies are used to create cell body distribution maps of antigenically homologous primary mechanosensory cells responding to noxious or pressure stimulation which form a subset of the cells stained by the antibody. Furthermore, antibodies against the pressure cells helped in the location of two different specific antigens for the same identified nerve cell.
\end{abstract}

Monoclonal antibodies (Kohler and Milstein, 1975) are a new tool for studying molecular neuroanatomy and have already been used to map the distribution of chemically homologous neurons within adult and developing nervous systems (Barnstable, 1980; Zipser and McKay, 1981; Trisler et al., 1981; Kushner and Reichardt, 1981; Sternberger et al., 1982; Hawkes et al., 1982). In one such study, two antibodies specific for ciliary ganglion cells bound to a small subset of cells in the neural crest from which the ciliary ganglion originates (Barald, 1982). Antibodies against peptides in the retina have been used to divide amacrine cells into morphologically distinct subpopulations (Brecha et al., 1979, 1981); amacrine cells stained by antisera against neurotensin were found to have an axodendritic projection different from that of amacrine cells stained by antibodies to enkephalin, somatostatin, or substance $P$.

In a simple organism like the leech, monoclonal antibodies can be used to map the distribution of all neurons which exhibit a particular antigenic determinant. I will refer to these sets of neurons as "antigenically homologous." A given monoclonal antibody can stain a set of

' The antibodies used for this work were generated in collaboration with Ron McKay. I wish to thank Carol Schley for her histological and tissue culture work and Mike Okler for his help in preparing the illustrations. This work was supported by National Science Foundation Grant BNS 78-248-72, National Institutes of Health Grant NS 1798401 , and a Whitehall grant.

${ }^{2}$ To whom correspondence should be addressed at Cold Spring Harbor Laboratory, P.O. Box 100, Cold Spring Harbor, NY 11724. neurons that either shares the same antigen or the same antigenic determinant common to more than one molecule (Dulbecco et al., 1981; Pruss et al., 1981). Also, a given neuron can be stained by more than one antibody. Since each neuron contains many specific molecular markers, it can be antigenically homologous with many sets of neurons.

In this paper, I report the complete distribution patterns of antigenically homologous neurons prepared with three different monoclonal antibodies (Zipser and McKay, 1981) that bind to single kinds or small sets of different neurons. I also present partial central nervous system maps of antigenically homologous neurons prepared from antibodies that bind to larger sets of many different kinds of neurons. In this report, I address the following questions: (1) how many different kinds of neurons belong to a given staining pattern? (2) What is the central nervous system distribution of each type of stained nerve cells? (3) Do all neurons to which the antibody can bind stain with the same regularity and intensity? (4) To what extent do labeled processes extend throughout the central nervous system?

General anatomy of the leech nerve cord. The 33ganglion leech nerve cord has several morphologically distinct sections, all of which are connected by a threefiber tract or connective. Of the 32 ganglia closely related embryologically, 4 are fused to form the head brain; the next 21 ganglia are unfused and constitute the chain of segmental ganglia; the last 7 ganglia are fused to form the tail brain. The 1 remaining ganglion of the nerve cord-the supraesophageal ganglia, the anteriormost 


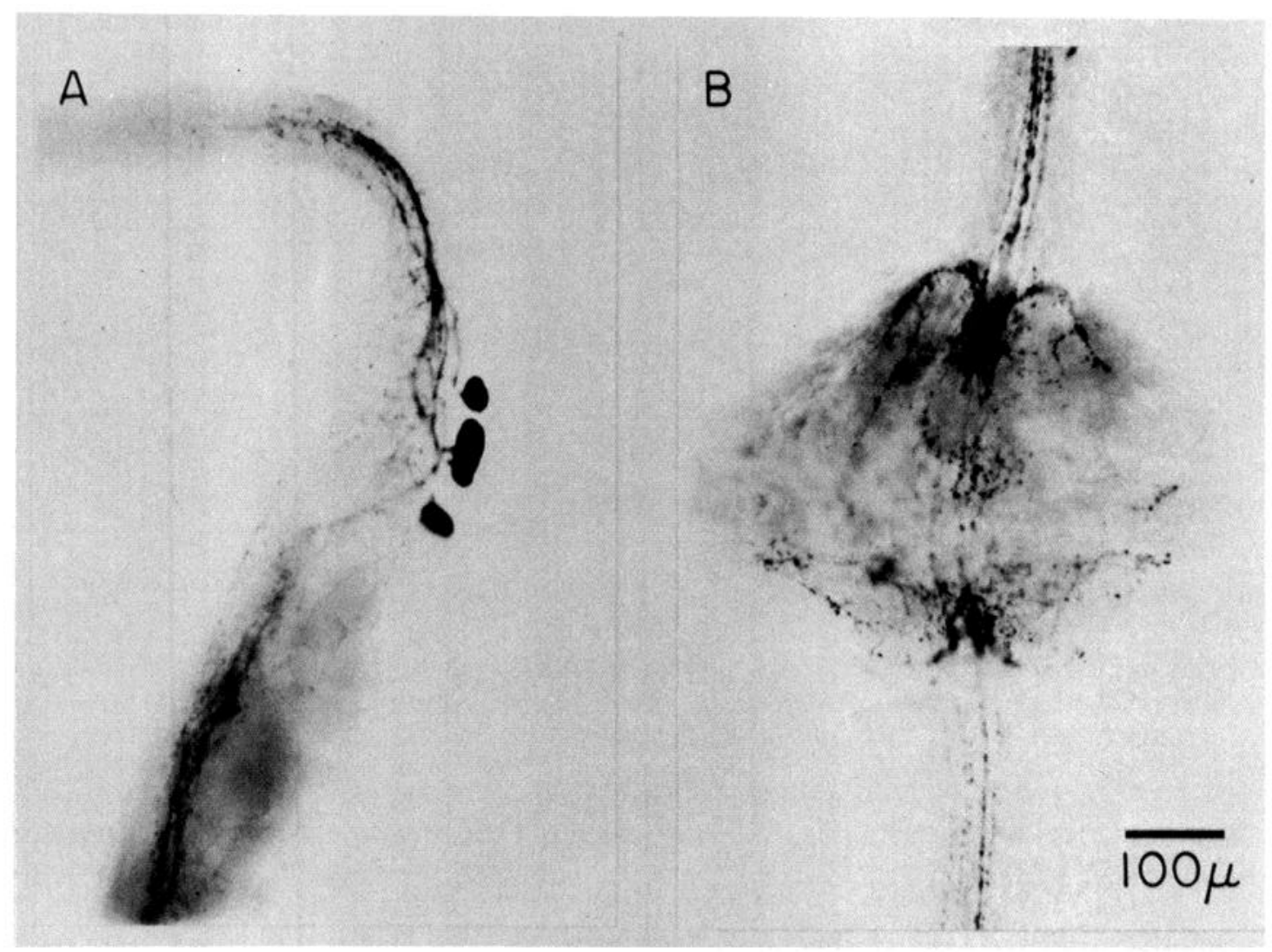

Figure 1. Monoclonal antibody Lan3-9 stains 5 cell bodies and many processes in the right supraesophageal ganglion $(A)$. In a segmental ganglion $(B)$, Lan3-9 only binds to processes. Focusing through the ganglion clearly reveals the 5 cell bodies in the whole mount, but they cannot be seen in the photograph because some lie underneath others.

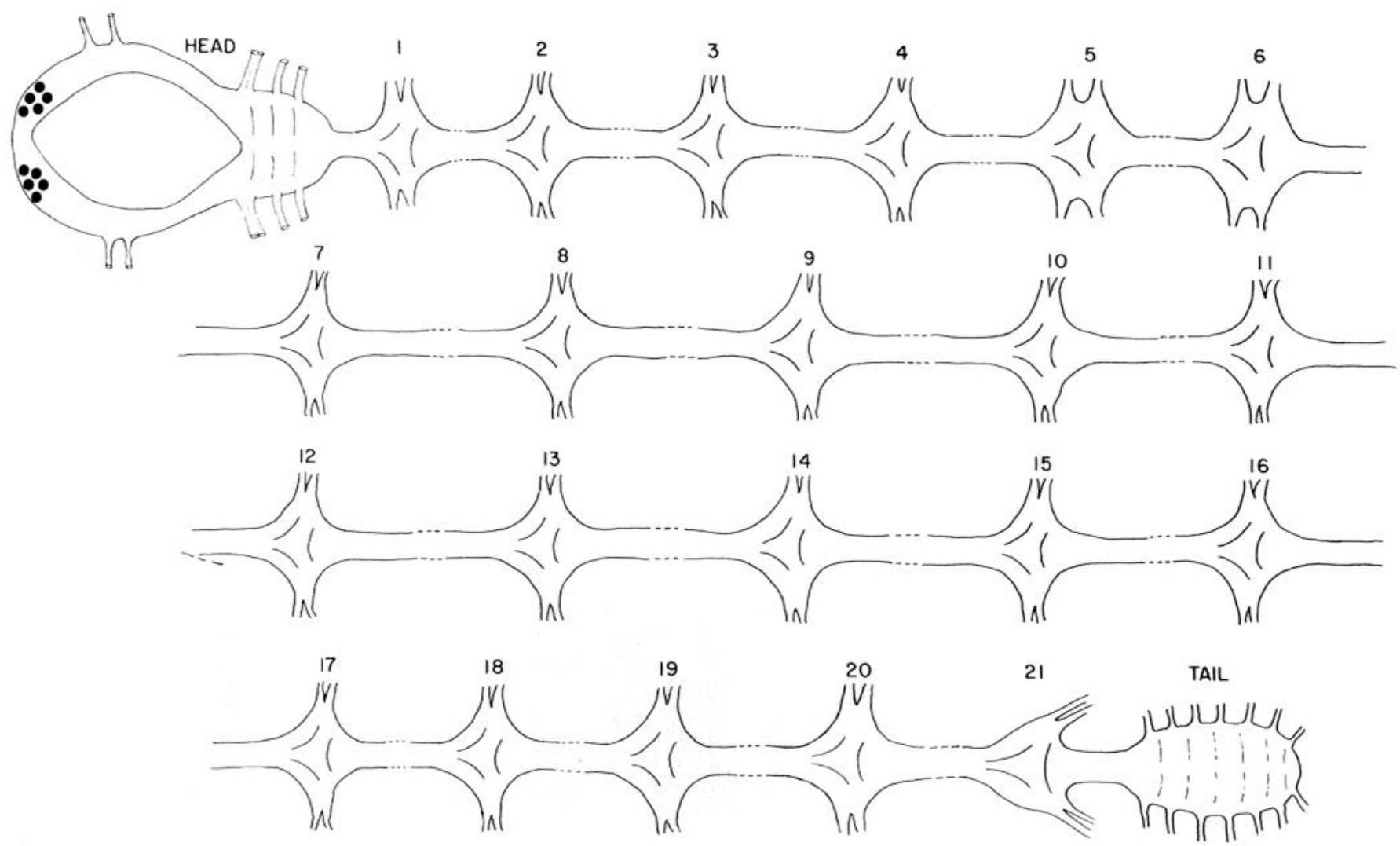

Figure 2. Whole leech nerve cord diagram with 10 Lan3-9 labeled cell bodies in the supraesophageal ganglion. 


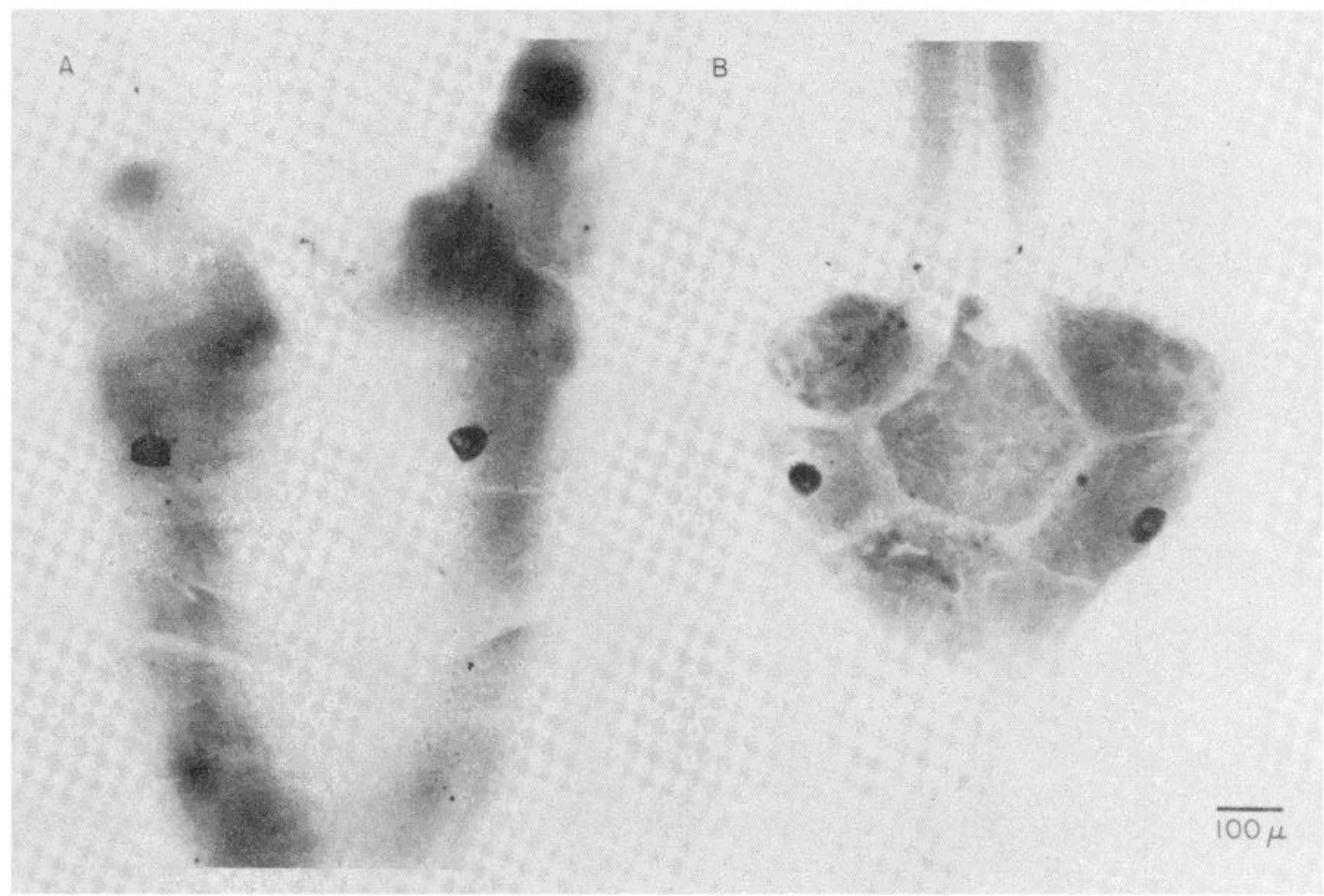

Figure 3. Lan3-11 binds to two pairs of 40- $\mu \mathrm{m}$ cell bodies. One pair occurs in head subganglion $2(A)$; the other is in segmental ganglion $2(B)$.
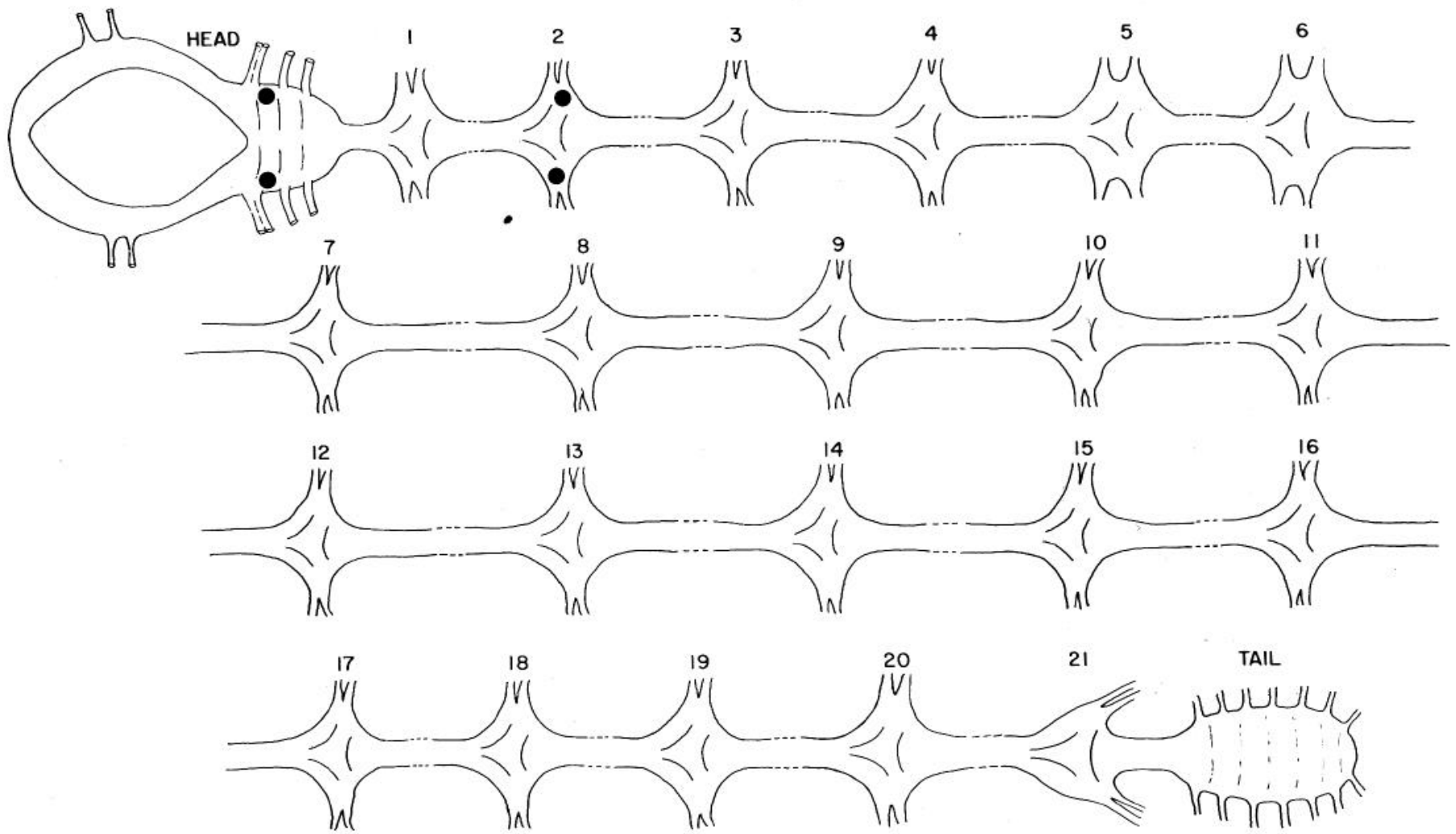

Figure 4. Whole leech nerve cord diagram with Lan3-11-labeled cell bodies.

brain center-has a different embryological origin (Weisblat et al., 1980) and is noted for its neurosecretory function (Hagadorn et al., 1963).

Accurate counts of neurons have been carried out for typical examples of a standard ganglion, such as ganglion 10 , and for some ganglia with specialized function, such as ganglia 5 and 6 (Macagno, 1980). The standard ganglion has about 400 cell bodies. In ganglia 5 and 6 , there 


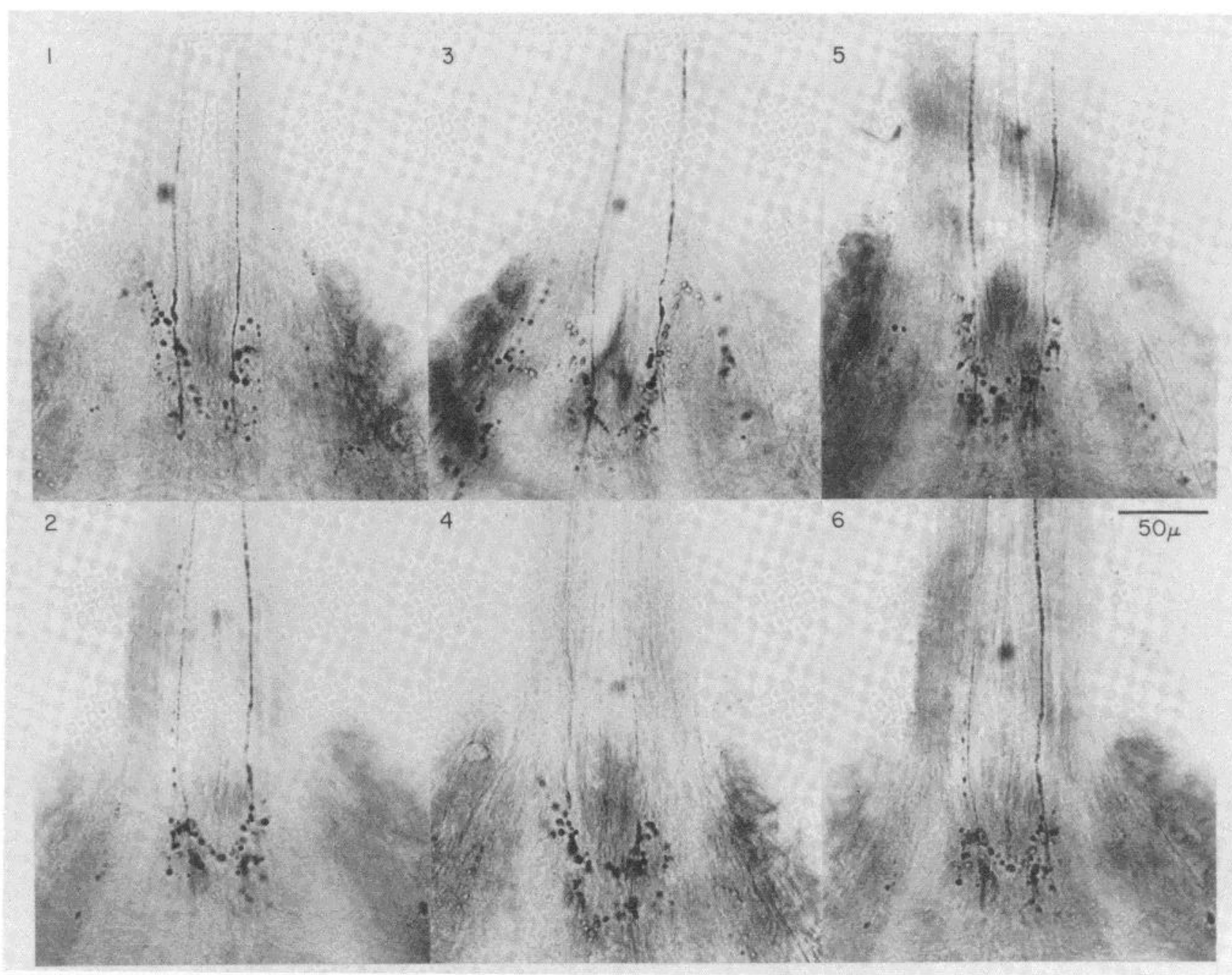

Figure 5. Lan3-11-labeled processes in 6 consecutive ganglia. A pair of thin labeled axons run in the connectives. Inside of the ganglion, the antibody binds to varicosities resembling typical leech synaptic terminals.

are extra neurons that subserve reproductive behavior (Zipser, 1979a, b). Ganglion 6, for example, with its 732 neurons, is almost twice as large as the standard ganglion.

Leech central nervous system neurons are unipolar. Their 20 - to $90-\mu \mathrm{m}$ cell bodies are located on the outer rim of each ganglion on both the ventral and dorsal surfaces. These cell bodies give off a thick primary axon that grows into the central synaptic neuropil, where it sprouts off neurites before exiting into the roots that connect the central nervous system to the periphery or into the central fiber tract or connective.

\section{Materials and Methods}

The leech species Haemopis marmorata, commonly called the mudleech, is purchased from bait supply stores in the northwestern United States. The leeches are stored for as long as a year in moist peat moss between $5^{\circ}$ and $8^{\circ} \mathrm{C}$.

For the immunocytochemical or simple dye injection studies, the leeches are anesthetized with alcohol before the nerve cord is dissected out. The live nerve cord is put into leech Ringer's solution and pinned out in a Sylgard dish. In a double labeling experiment, neurons are impaled under visual control, identified by their electrical parameters, and pressure-injected with Lucifer yellow (Aldrich; $3 \%$ in $\mathrm{H}_{2} \mathrm{O}$ ). Then they are treated for immunocytochemistry. In this report, the immunocytochemical stains were carried out only on fixed tissue. The nerve cords are fixed either in $4 \%$ paraformaldehyde in $0.1 \mathrm{~m}$ phosphate buffer for $1 / 2 \mathrm{hr}$ or in Bouin's solution for $4 \mathrm{hr}$. After the fixative is rinsed off, the connective tissue capsule of each ganglion is removed mechanically with specially sharpened Dumont No. 5 forceps. The tissue is unpinned and processed further in test tubes. It is permeabilized to antibody penetration by xylene extraction and by adding Triton X-100 (0.3 or $2 \%)$ to each antibody solution. The antibody staining is carried out in two steps at room temperature. First, the tissue is incubated overnight with a hybridoma growth medium or with ascites fluid at the appropriate dilutions. The next day, after a PBS wash, the ganglia are incubated for $2 \mathrm{hr}$ with a second antibody, either HRP or rhodamine-conjugated goat anti-mouse IgG (Cappel; $1: 30$ ). Next, the ganglia are pinned out again. If a rhodamine-conjugated second antibody was used, the tissue is dehydrated, cut free from 
A

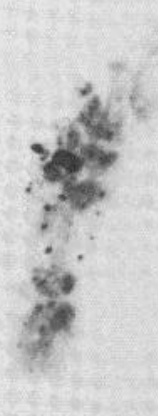

D
B

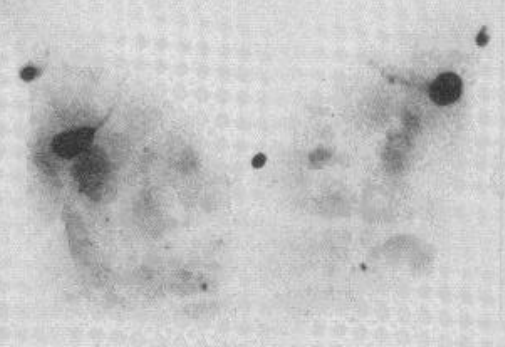

E
C

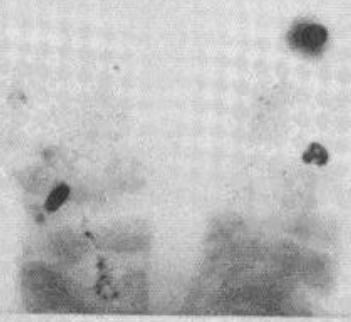

$\mathrm{F}$
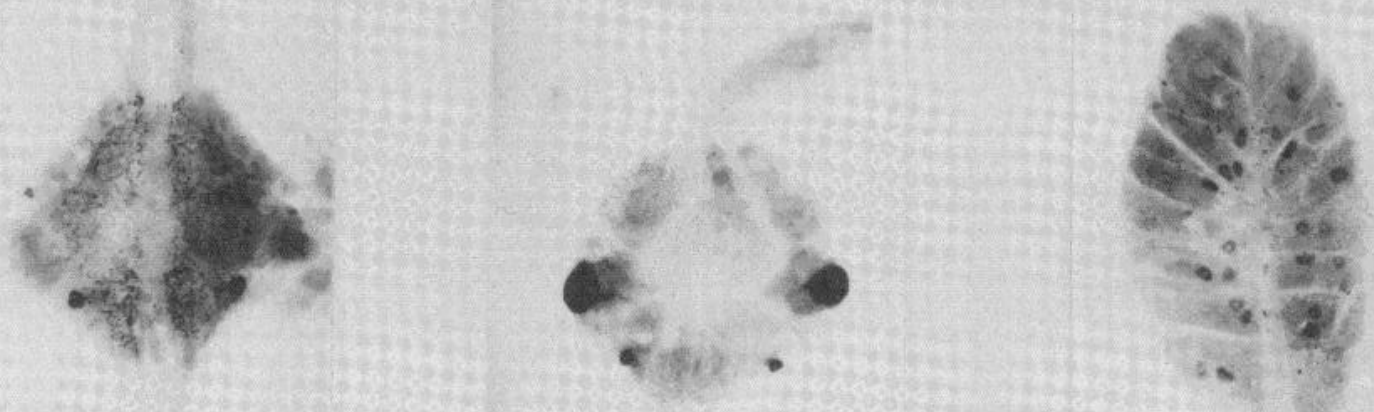

$\overline{100 \mu}$

Figure 6. Lan3-1-labeled cell bodies and processes. A, Supraesophageal ganglia: Bilateral nucleus consisting of $450-\mu \mathrm{m}$ cell bodies (staining frequency in 16 preparations, $40 \%$ ) and $125-\mu \mathrm{m}$ cell body ( $80 \%$ stained). The $35-\mu \mathrm{m}$ pair of cells close to the midline (Fig. 7) did not stain in this preparation (staining frequency, 35\%). B, Ventral subesophageal ganglia: subganglion 1, a 20$\mu \mathrm{m}$ unpaired medial cell body (staining frequency in 20 preparations, $75 \%$ labeled); a $60-\mu \mathrm{m}$ pair of cell bodies $(60 \%$ stained); a $25-$ $\mu \mathrm{m}$ pair of cell bodies (45\% stained). C, Dorsal subesophageal ganglia; subganglion 1, a $35-\mu \mathrm{m}$ pair of cell bodies (35\% labeled); subganglion 2, another $35-\mu \mathrm{m}$ pair of neurons (10\% stained). $D$, Standard segmental ganglion: a $20-\mu \mathrm{m}$ pair of cell bodies on the dorsal surface with prominent varicosities in the ganglionic neuropil. $E$, Segmental ganglion 6 : a double exposure puts the 20- $\mu \mathrm{m}$ dorsal and the $60-\mu \mathrm{m}$ ventral pair of cell bodies into focus. Varicosities are present but do not show up. $F, 7$ fused tail subganglia with stained cell bodies.

the pins, and embedded in a methacrylate mounting medium (Stewart, 1978). If an HRP-conjugated second antibody is used, the tissue is rinsed in Tris buffer and treated with Millipore-filtered diaminobenzidine (Bionetics; $0.03 \%$ in Tris) and $\mathrm{H}_{2} \mathrm{O}_{2}(0.01 \%)$ under a dissecting scope. After the neurons are stained to the desired intensity, the tissue is rinsed, alcohol-dehydrated, passed through xylene, and embedded in Permount.

\section{Results}

Complete central nervous system distribution patterns of antigenically homologous neurons. The simplest antibody staining patterns for the leech central nervous system contain single kinds or small sets of different neurons. Examples are the staining patterns of monoclonal anibodies Lan3-9 and Lan3-11. Lan3-9 binds to 10 $30-\mu \mathrm{m}$ large cell bodies in the supraesophageal ganglion, the highest brain center. The neurons are arranged as bilateral groups with 5 cell bodies each (Figs. $1 A$ and 2).
These tight, little clusters of cell bodies are suggestive of functional nuclei. Such nuclei would constitute a new facet of the leech nervous system. Lan3-11 binds to 4 neurons, each $40 \mu \mathrm{m}$ in diameter. These neurons occur as bilateral pairs, with one in subesophageal ganglion 2 , and the other in segmental ganglion 2 (Figs. $3, A$ and $B$, and 4). In addition to staining cell bodies, both antibodies also stain processes that extend throughout the entire leech central nervous system. Several Lan3-9-labeled axons run in the connective, the central fiber tract that links all ganglia in the nerve cord (Fig. $1 B$ ). Within the center of each ganglion in the synaptic neuropil, Lan3-9 highlights a mass of varicosities, which resemble typical leech synaptic terminals (Muller and McMahan, 1976). Similar kinds of varicosities also are stained by Lan3-11, but they appear to be fed only by one pair of axons entering the ganglion from the connective, as illustrated with 6 successive ganglia (Fig. 5). As is apparent from the six micrographs, axoneuritic Lan3-11-labeled processes repeat from 1 segmental ganglion to the next 


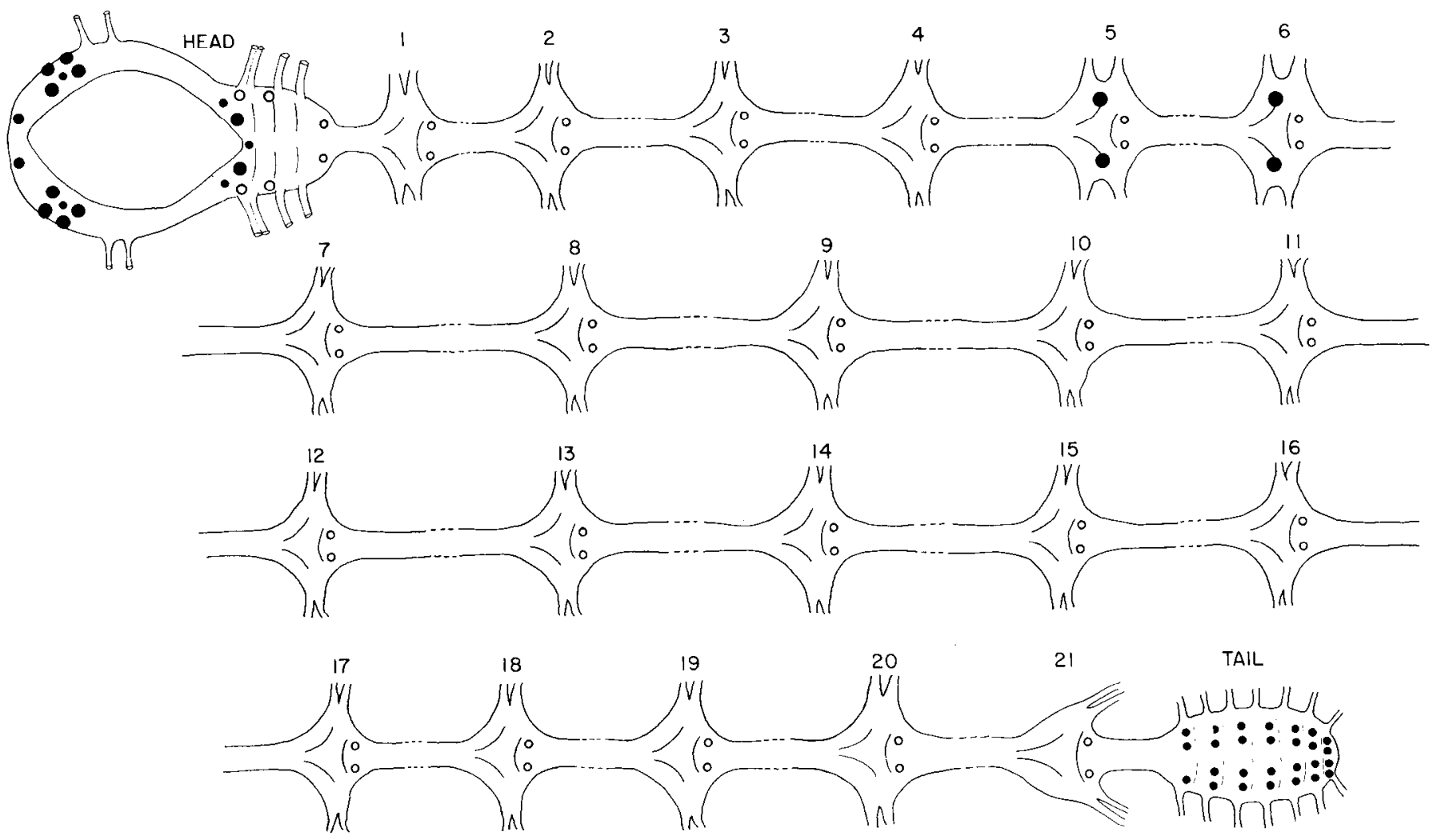

Figure 7. Whole leech nerve cord diagram showing Lan3-1-labeled cells; ventral cell bodies are indicated as solid circles and dorsal cell bodies are shown as open circles.

ganglion in the same "stereotypic" way that is well documented for segmental cell bodies in the leech nerve cord (Nicholls and Baylor, 1968; Stuart, 1970; Keyser et al., 1982).

Both Lan3-9 and Lan3-11 have visualized a type of neuron different from that commonly studied in the leech. While most leech electrophysiology has centered on neurons that repeat in the segmental midbody ganglia, these newly discovered antigenically homologous neurons are present in only 1 or 2 ganglia and therefore might be assigned a more localized function, similar to the "sex" neurons in ganglia 5 and 6 (Zipser, 1979a, b) to which the monoclonal antibody Lan3-1 binds. These two pairs of sex neurons share electrophysiological homologies (action potential parameters and synaptic potentials), but they are not functionally equivalent. The ganglion 6 neurons are penile evertor motor neurons, while the ganglion 5 neurons are not. In addition to binding to these identified sex neurons, Lan3-1 also reacts with several other cell types along the nerve cord whose diameter ranges from 20 to $60 \mu \mathrm{m}$. Each of these neurons has its own characteristic frequency and central nervous system distribution (Figs. 6 and 7). The two pairs of sex motor neurons occur in sex ganglia 5 and 6 (Fig. $6 E$ ); another set of two bilateral pairs of neurons occurs in head subganglia 1 and 2 on the dorsal surface (Fig. $6 C$ ). Four other types of neurons occur as a single pair either on the ventral surface of the subesophageal ganglion (Fig. $6 B$ ) or in the supraesophageal brain (Fig. 6A). One pair in the supraesophageal ganglion is associated with a bilateral group of 3 cell bodies, thereby creating a little Lan3-1-stained nucleus. The only single unpaired Lan31-labeled neuron occurs in the head brain. Other Lan3- 1-labeled neurons can be found in the tail brain (Fig. $6 F$ ). In addition to these various kinds of special neurons, the Lan3-1 staining pattern also contains a cell type that we usually associate with the leech central nervous system. It is a small, $20-\mu \mathrm{m}$ cell body that repeats in 22 ganglia, from head subganglion 1 all along the segmental nerve cord down to the tail (Fig. 6, $D$ and $E$ ).

A prominent feature of the Lan3-1 staining pattern is its strongly labeled varicosities in the synaptic neuropil (Fig. 6D). The origin of these varicosities is still uncertain, because they are linked by thin, only intermittently stained neurites. They could derive from a suprasegmental source as well as from the small pair of $20-\mu \mathrm{m}$ cell bodies located in each ganglion. Although these segmen-. tal cell bodies are darkly labeled and one often can make out the onset of the primary axon, it has been difficult to follow the axon for more than 10 to $20 \mu \mathrm{m}$ into the neuropil. The axon of the small cell body was stained homogeneously enough so that it could be followed over a long distance in only one preparation. It appeared to bend anteriorly as it reached the middle of the ganglion, slope forward, and then constrict to exit as a very fine axon into the anterior connective. A similar type of thin Lan3-1-labeled axon has been observed previously but not in every preparation. If this axon were confirmed to stem from the segmental cell body, a suprasegmental source for the varicosities would become less likely. The large sex neurons in ganglia 5 and 6 can already be ruled out as the source of the varicosities. Their axoneuritic geometry was determined earlier through intracellular horseradish peroxidase injection (Zipser, 1979a).

Complete distribution patterns of subsets of stained neurons. Subset distribution maps of recognizable cells 


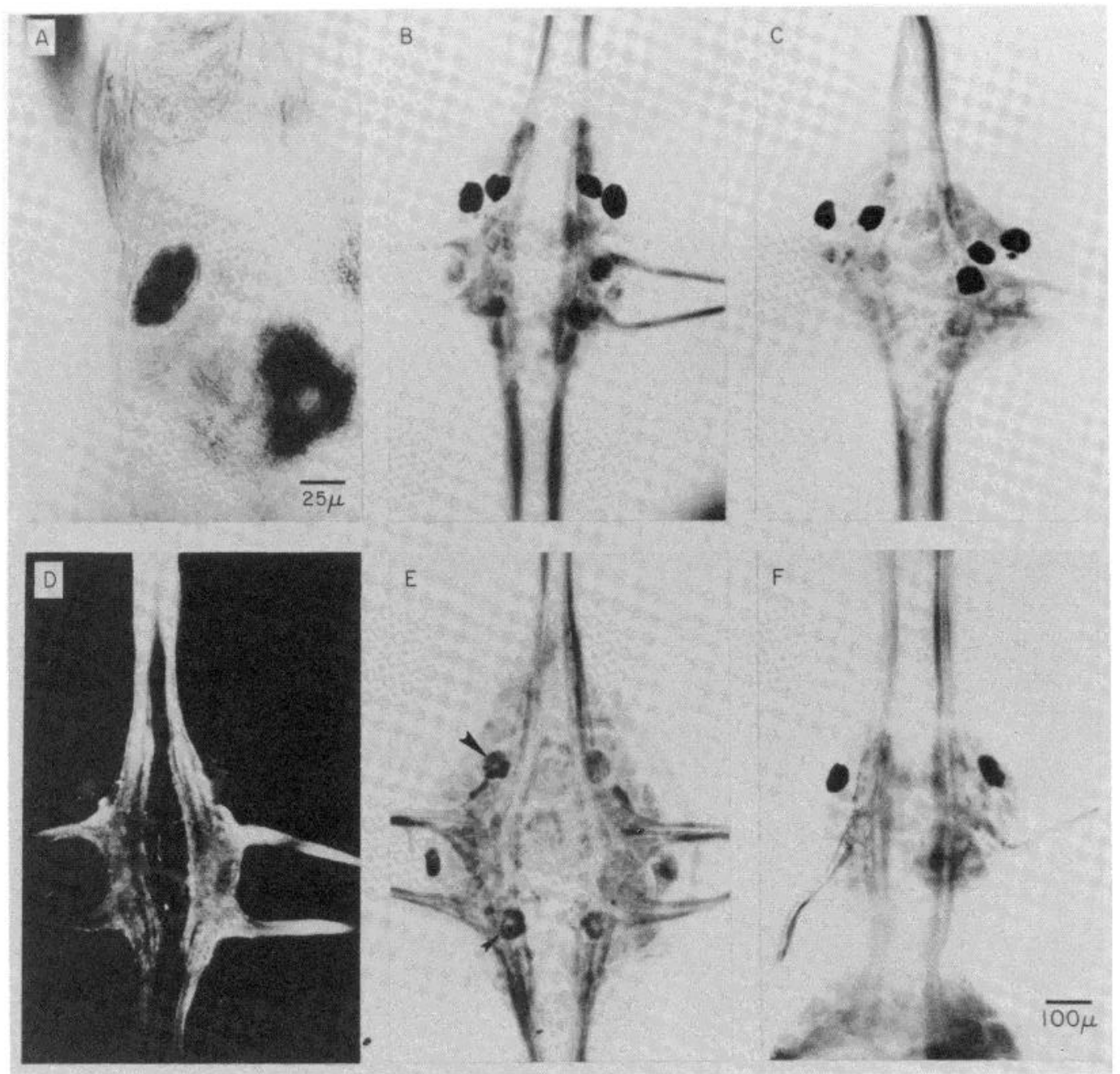

Figure 8. Lan3-2-labeled cell bodies and processes. $A$, Left subesophageal ganglion 4 with two deeply stained nociceptive cell bodies. $B$, A standard segmental ganglion with two pairs of deeply stained nociceptive neurons. $C$, A standard segmental ganglion with a developmental deviation has 5 stained cell bodies. $D$, Ganglion 6 , in which Lan3-2 is visualized with a rhodamine-conjugated second antibody, shows no labeled cell bodies. $E$, Ganglion 6 from a nerve cord with noticeable pressure cell staining (small arrowhead). A single pair of cell bodies in the anterior half of the ganglion is labeled (arrowhead) points to the left cell body. $F$, Ganglion 21 with just one pair of stained nociceptive neurons.

were prepared with antibodies Lan3-2, Lan3-5, and Lan3-6, which bind to large sets of neurons. The most prominent feature of the Lan3-2 staining pattern is the brilliant labeling of primary mechanosensory neurons that respond to noxious stimulation of the skin (Nicholls and Baylor, 1968). There are 4 such neurons in the standard segmental ganglion (Fig. 8B). Lan3-2 binds to both the lateral and medial nociceptive neurons, which differ in some of their receptive field properties (Blackshaw, 1981) and synaptic connectivities. The analysis of the Lan3-2 staining pattern is complicated by the fact that the antibody also can label other types of neurons though more weakly. First, there can be weak, generalized labeling of all cells. Second, the pressure cells usually are stained to some degree. They are barely noticeable in Figure $8 B$ but are more strongly stained in Figure $8 E$ (the small arrowhead points to the posterior left pressure cell). Within the same nerve cord, the degree of generalized and pressure cell staining is similar from one ganglion to the next. In nerve cords from 76 leeches, the pressure cells were not stained above background $16 \%$ of the time; they were weakly labeled $78 \%$ of the time and were almost as strongly labeled as the nociceptive neurons $5 \%$ of the time.

There are several reasons why the same monoclonal antibody can stain nerve cells with different intensities. Different nerve cells might have different antigen concentrations. Alternately, the same antibody might bind to different molecules in pressure cells and nociceptive neurons which share a common antigenic determinant (Dulbecco et al., 1981). In this case, different staining intensities could arise either because of concentration differences or different binding affinities.

Because strong nociceptive staining is the most salient feature of the fixed, Triton X-100-permeabilized ganglion, Lan3-2 is a suitable antibody for preparing a map of antigenically homologous nociceptive neurons for the entire extent of the central nervous system (Fig. 9). 


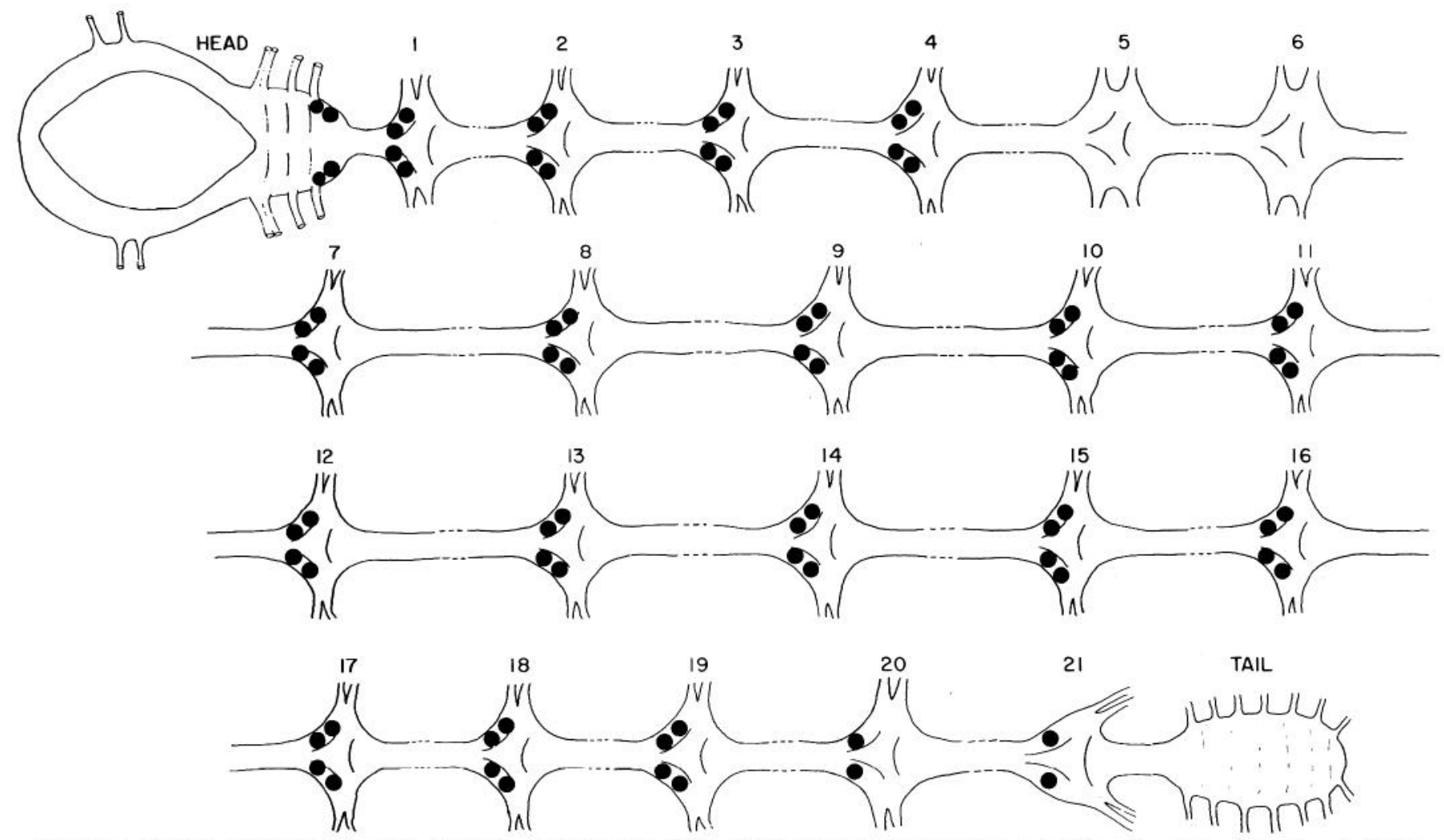

Figure 9. Whole leech nerve cord diagram with nociceptive cell bodies that are always brilliantly stained by Lan3-2. The pressure cells and the single pair of neurons in ganglia 5 and 6 that usually are stained to the same lesser degree as the pressure cell are not entered.
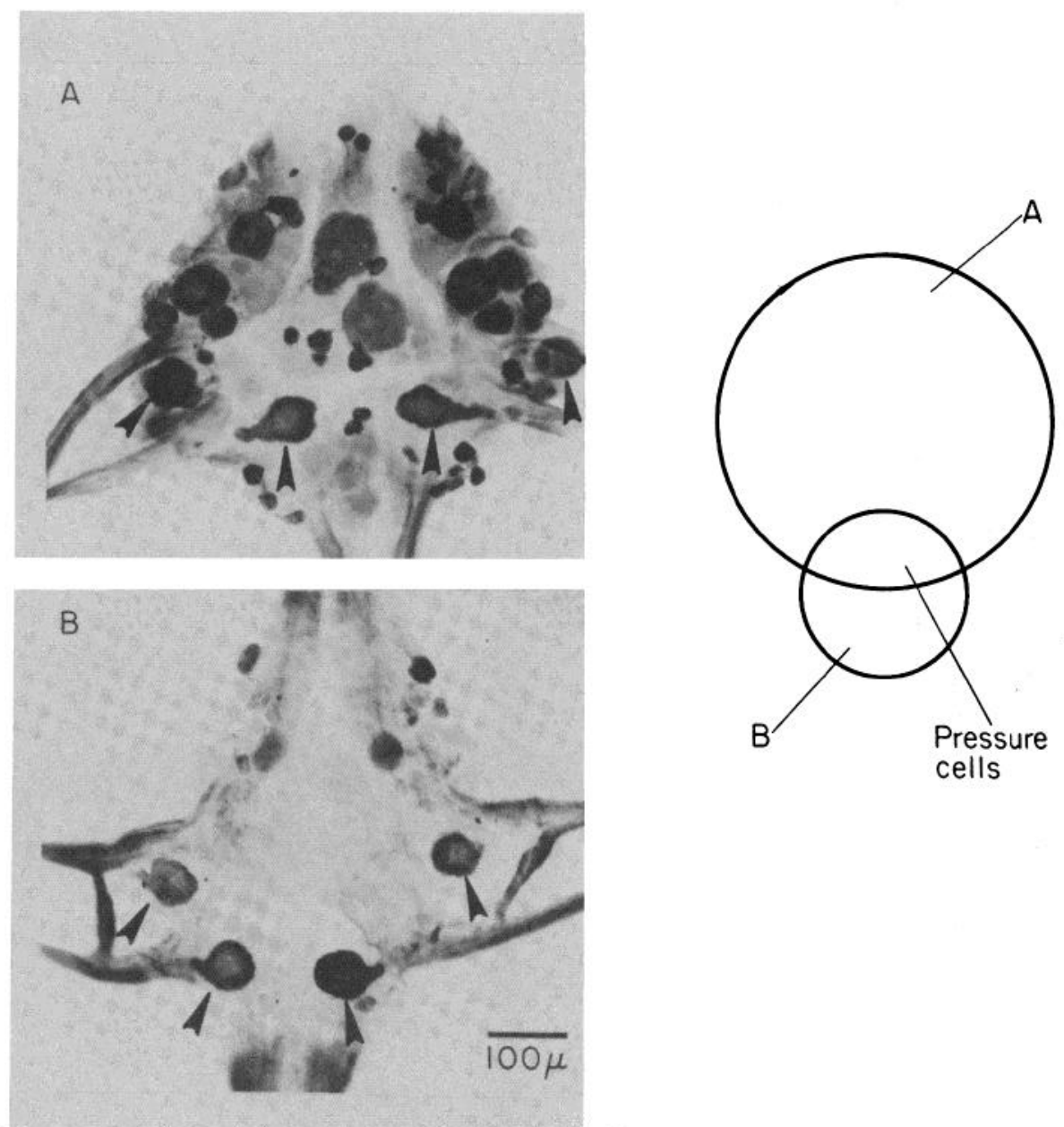

Figure 10. The staining patterns of two antibodies, Lan3-6 $(A)$ and Lan3-5 $(B)$, that overlap in the pressure cells (arrowheads). Both antibodies bind to 4 pressure cells in a standard 400-neuron ganglion. 


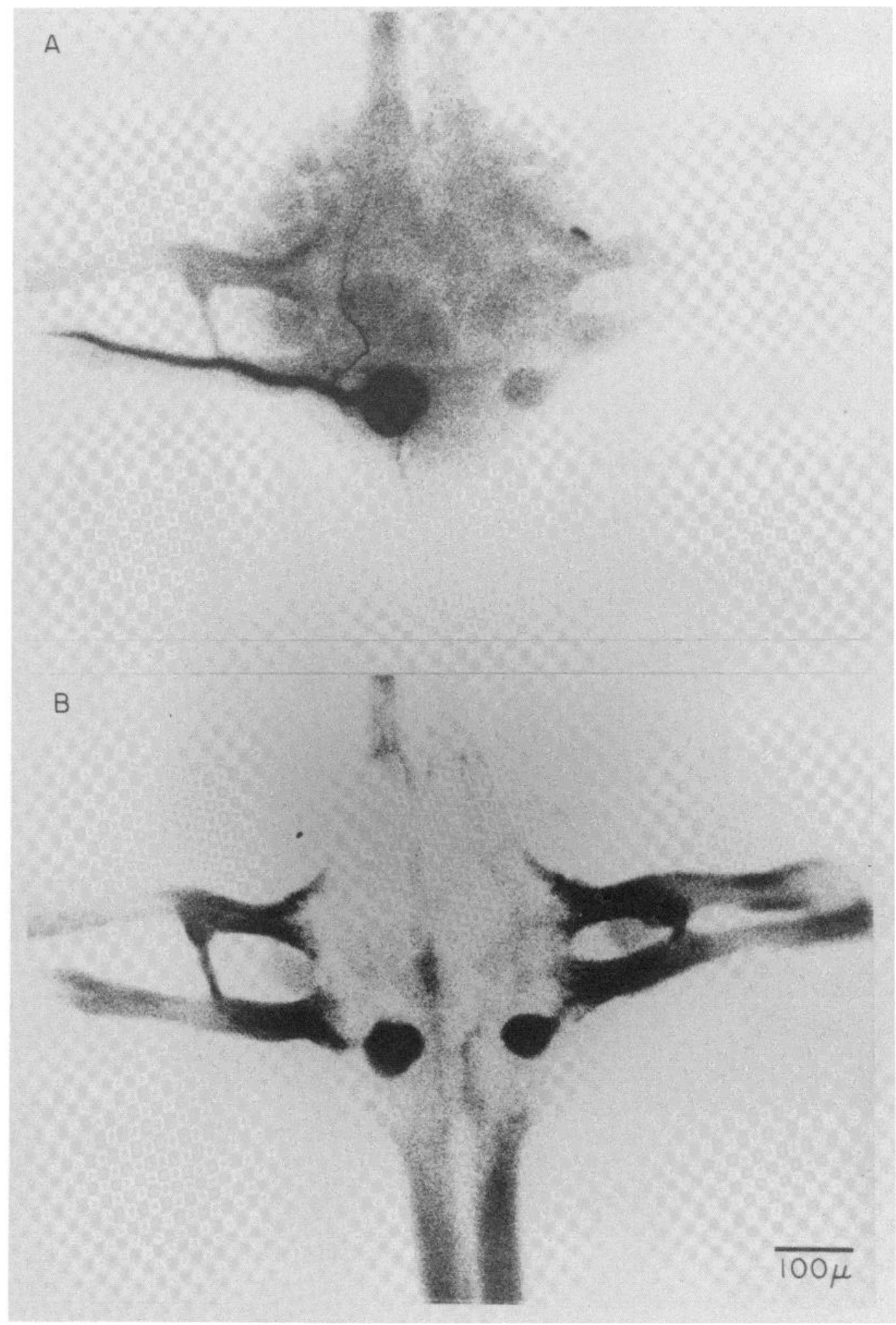

Figure 11. A double-labeling experiment verifies that the pressure cell has the Lan3-5 antigen. $A$, In the live ganglion, the left posterior pressure cell is injected with Lucifer yellow and viewed under FITC optics. $B$, The identical ganglion, treated with Lan3-5, followed by a rhodamine-conjugated second antibody, is viewed under RITC.

Deeply stained cell bodies are always found in head subganglion 4 and in segmental ganglia 1 to 4 ; they are absent from ganglia 5 and 6 but reappear from ganglia 7 to 19 . The last 2 segmental ganglia before the fused tail brain, ganglia 20 and 21 , have only a single pair of deeply stained cell bodies that correlate with their reduced cell count of only 350 cell bodies (Macagno, 1980). The tail ganglia lack deeply stained nociceptive cell bodies, simi- 


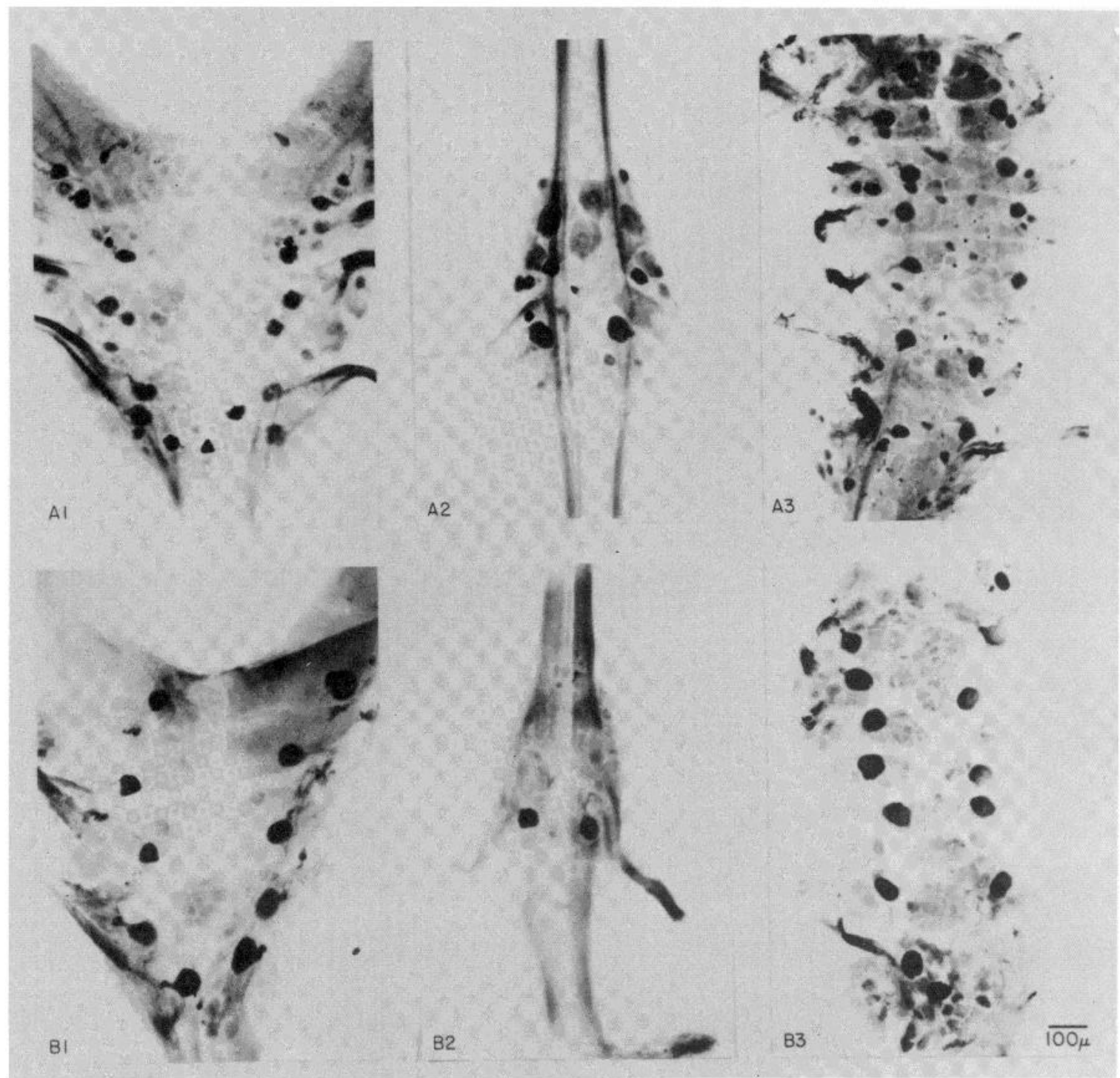

Figure 12. Lan3-6 and Lan3-5 stain pressure cell bodies in 4 fused head subganglia ( $A 1$ and $B 1)$, ganglia 20 ( $A 2$ and $B 2$ ), and the fused tail subganglia ( $A 3$ and $B 3)$.

lar to ganglia 5 and 6 , but they do have cell bodies stained with an intensity similar to the segmental pressure cells.

Whether nociceptive cell bodies are really absent from ganglia 5 and 6 is an unresolved question. In nerve cords lacking generalized background and pressure cell staining, ganglia 5 and 6 have no labeled nociceptive cell bodies. However, in ganglia in which the pressure cells are noticeably stained, a single pair of cell bodies is detectable where the double pair of nociceptive neurons occur in other segmental ganglia. In 18 nerve cords studied, 70 of 72 such neurons were stained with the low intensity characteristic of pressure cells and only 2 cells were stained as deeply as the typical nociceptive neuron.

In addition to determining genetic variation in antigen distibution, Lan3-2 also serves as a convenient marker to reveal developmental errors. In Figure $8 C$, Lan3-2 brilliantly stains a 5 th supernumerary cell body resembling the other nociceptive cell bodies in size and ganglionic position. The 5th, deeply stained neuron was found in one of the ganglia of a 3-ganglion test strip; the other
2 ganglia had the normal number of strongly labeled neurons. Previous observations of supernumerary mechanosensory or Retzius cells were largely anecdotal and only substantiated in rare cases through laborious electrophysiological experiments (Kuffler and Muller, 1974). For example, an extra Retzius cell was once found in just 1 ganglion in a Hirudo leech nerve cord. In another case, odd mechanosensory cells occurred in several ganglia of 1 leech. Thus, in the earlier cases, supernumerary neurons were identified by their cell body positions, diameters, their electrophysiological parameters, and sometimes even by their input or output relationships. In the instance reported here, a supernumerary cell, by contrast, is identified as a member of an antigenic peer group. This cell's position and size suggest that it is an extra nociceptive neuron, but this could not be confirmed electrophysiologically because fixation had preceded detection by antibody staining.

Two antibodies that overlap in their staining patterns. Of all of the antibodies illustrated here, Lan3-5 
and Lan3-6 stain the most neurons (Fig. 10). These two antibodies bind from 5 to $10 \%$ of all cell bodies in the standard unfused midbody ganglion; among these are primary mechanosensory cells which respond to pressure applied to the skin (Nicholls and Baylor, 1968). A standard ganglion has 4 such $60-\mu \mathrm{m}$ cells, which exist as two bilateral pairs with different receptive field properties, with the lateral pair innervating the ventral and the medial pair innervating the dorsal body wall. Double labeling experiments verified that our antibodies bind to both classes of pressure cells.

The typical double labeling experiment to identify an antibody-labeled neuron is illustrated in Figure 11. In a live ganglion, a cell body that appears to belong to a pressure cell was impaled with a Lucifer yellow-filled microelectrode and identified by its action potential. Then, this left posterior pressure cell was pressure-injected with Lucifer yellow (Stewart, 1981), fixed, and reacted with antibody Lan3-5. The monoclonal antibodies were visualized with a rhodamine-conjugated second antibody. The identical cell body fluoresces yellow under fluorescein isothiocyanate (FITC) optics because of its intracellular Lucifer yellow content (Fig. 11A) and red under rhodamine isothiocyanate (RITC) optics because the antibodies bind to it (Fig. $11 B$ ). Another double labeling experiment proved that Lan3- 6 bound to the pressure cell as well.

Thus, we have identified two different pressure cell antigens. The Lan3-5 and Lan3-6 staining patterns overlap on both the medial and lateral pressure cells in the typical unfused midbody ganglion (Fig. 10). Using both of these antibodies, a map of the variations in pressure cell distribution was constructed for the entire extent of the leech central nervous system (Figs. 12 and 13). In this map, specialized ganglia show less deviation in their pressure cell count than was the case for the Lan3-2labeled nociceptive cell bodies.

The full set of 4 pressure cells occurs in unfused ganglia 1 to 19 and in head subganglion 4 (Figs. 12 and 13). The other ganglia that are closely related embryologically have just 2 pressure cells; these are ganglia 20 and 21 , the 7 fused tail ganglia, and the subesophageal ganglia 1 , 2 , and 3. The cell distribution map in Figure 13 presents the minimum number of pressure cells in the nerve cord. Additional cells that lack the Lan3-5 antigen might be present since Lan3-6 labels more than one pair of large cell bodies in head subganglia 2,3 , and 4 . However, cell bodies have been scored as pressure cells only if they appear in both the Lan3-5 and Lan3-6 staining patterns.

\section{Discussion}

$\Lambda$ thorough analysis of monoclonal antibody staining patterns requires a detailed anatomical distribution map. This map should contain information on the different types of cell bodies, their frequency and distribution within the leech central nervous system, as well as the projections of antigenically related axons. After such a distribution map is prepared, it sometimes becomes possible to investigate why particular neurons belong to the same antigenic peer group. In some cases, the antigenic homologies have been shown to correlate with electrophysiological, morphological, and functional homology.

The most direct benefit of analyzing a staining pattern is that it provides us with a great deal of information

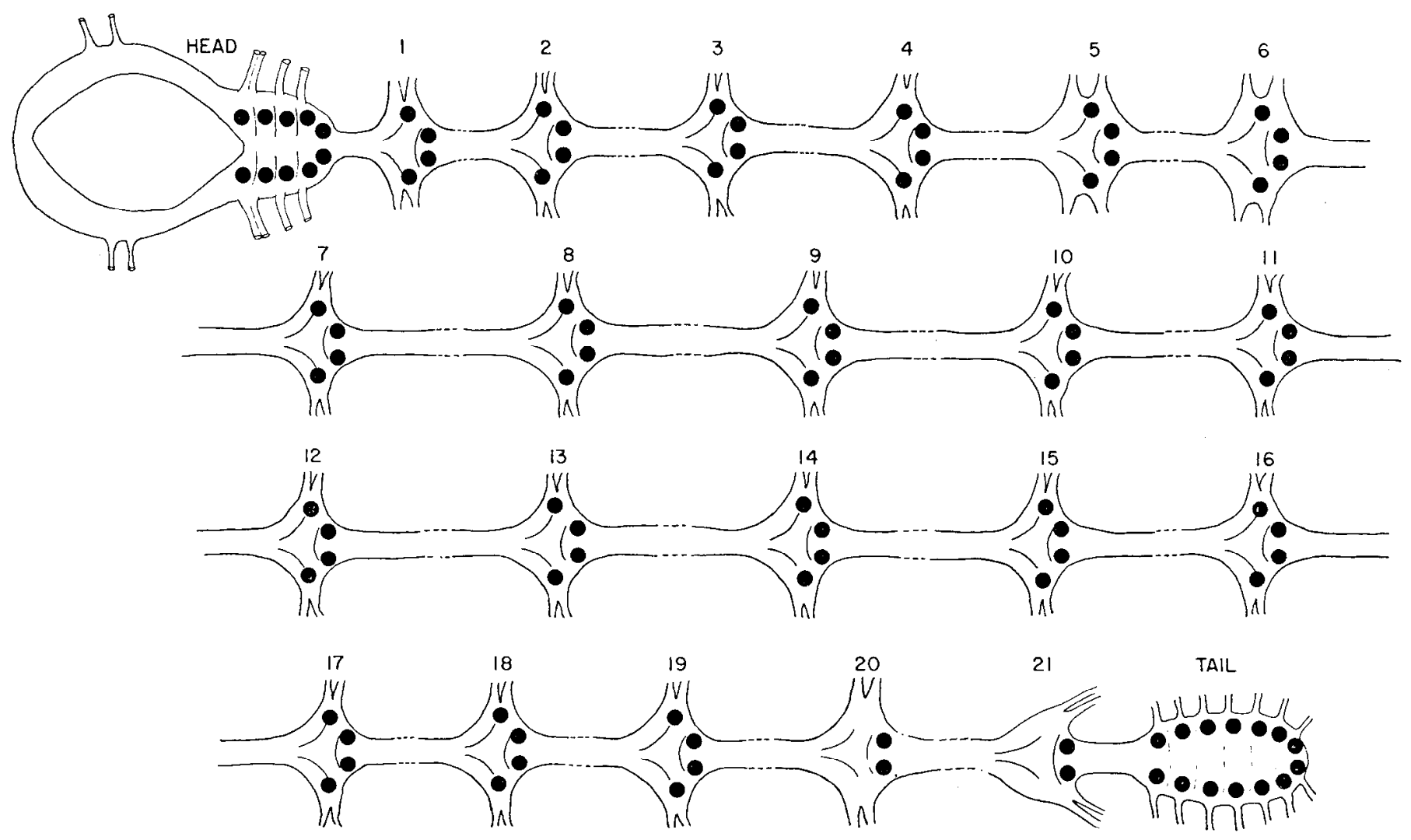

Figure 13. Whole leech nerve cord diagrams with pressure cells that jointly appear in the Lan3-5 and Lan3-6 staining patterns. 
useful to physiologists who study the integrative aspects of the leech nervous system (Kristan et al., 1974; Friesen et al., 1976; Calabrese, 1980). For example, Lan3-9 and Lan3-11 have revealed small sets of antigenically homologous cell bodies present only in 1 or 2 ganglia together with antigenically related processes projecting throughout the entire nerve cord. A plausible interpretation of these staining patterns is that they reveal a small set of control neurons influencing the entire leech nerve cord. These two antibodies have led to the identification of neurons that are of potential benefit for analyzing detailed neural processing in the leech. In addition, these antibodies enable us to begin to estimate the number of higher order control neurons that are necessary for maintaining a nervous system of the complexity of the leech.

Antibody Lan3-1 enables us to trace additional neurons that are part of the reproductive circuits. Interestingly, the newly discovered neurons in ganglion 5 are connected synaptically to the previously identified pair of penile evertor cells in ganglion 6 through electrotonic junctions. Since the antibody does not stain other identified sex neurons, such as the rostral penile evertor cells, one might argue that Lan3-1 identifies an electrotonically connected subnetwork within the larger reproductive network. The next question to answer will be whether all of the other cell types that carry the Lan3-1 antigen are involved in sexual function as well. If this turns out to be the case, the antibody would not only be of significance in the ongoing study of leech reproductive function but it may indicate that functional subnetworks often share common antigenic markers.

The three antibodies, Lan3-1, -9 , and -11 , discussed here bind to intracellular antigens. They do not bind to the surface membrane of leech cell bodies that are freely exposed to the antibody solution. Although the nature of the internal antigens is not yet known, these three antibodies still serve as useful markers.

\section{References}

Barald, K. (1982) Monoclonal antibodies to embryonic neurons: Cell specific markers for chick ciliary ganglion. In Neuronal Development, N. C. Spitzer, ed., pp. 101-119, Plenum Press, New York.

Barnstable, C. J. (1980) Monoclonal antibodies which recognize different cell types in the rat retina. Nature 286: 231-235.

Blackshaw, S. E. (1981) Sensory cells and motor neurons. In Neurobiology of the Leech, K. J. Muller, J. G. Nichols, and G. S. Stent, eds., pp. 51-78, Cold Spring Harbor Laboratory, Cold Spring Harbor, NY.

Brecha, N., H. J. Karten, and C. Laverack (1979) Enkephalin containing amacrine cells in the avian retina; Immunohistochemical localization. Proc. Natl. Acad. Sci. U.S.A. 76: 30103014.

Brecha, N., H. J. Karten and C. Schenker (1981) Neurotensin like and somatostatin like immunoreactivity within amacrine in the retina. Neuroscience 6: 1329-1340.

Calabrese, R. L. (1980) Control of impulse-initiation sites in a leech interneuron. J. Neurophysiol. 44: 878-896.

Dulbecco, R., M. Unger, M. Bologna, H. Battifora, P. Syka, and
S. Okada (1981) Cross-reactivity between Thy-1 and a component of the intermediate filament demonstrated using a monoclonal antibody. Nature 292: 772-774.

Friesen, W. O., M. Poon, and G. S. Stent (1976) An oscillatory neuronal circuit generating a locomotory rhythm. Proc. Natl. Acad. Sci. U. S. A. 73: 3734-3738.

Hagadorn, I. R., H. W. Bern, and R. S. Nishioka (1963) The fine structure of the supraesophageal ganglion of the Rhynchobdellid leech, Theromyzon Rude, with special reference to neurosecretion. Z. Zellforsch. Mikrosk. Anat. 58: 714-758.

Hawkes, R., E. Niday, and A. Matus (1982) Monoclonal antibodies identify novel neural antigens. Proc. Natl. Acad. Sci. U. S. A., 79: 2410-2414.

Keyser, K. T., B. M. Frazer, and C. M. Lent (1982) Physiological and anatomical properties of Leydig cells in the segmental nervous system of the leech. J. Comp. Physiol., 146: 393-400.

Kohler, G., and C. Milstein (1975) Continuous cultures of fusen cells secreting antibody of predefined specificity. Nature 256 : 495-497.

Kristan, W. B., G. S. Stent, and C. A. Ort (1974) Neuronal control of swimming in the medicinal leech. I. Dynamics of the swimming rhythm. J. Comp. Physiol. 94: 97-119.

Kuffler, D. P., and K. J. Muller (1974) The properties and connections of supernumerary sensory and motor nerve cells in the central nervous system of an abnormal leech. J. Neurobiol. 5: 331-348.

Kushner, P., and L. W. Reichardt (1981) Monoclonal antibodies against Torpedo synaptosomes. Soc. Neurosci. Abstr. 7: 12.

Macagno, E. R. (1980) Number and distribution of neurons in leech segmental ganglia. J. Comp. Neurol. 190: 283-302.

Muller, K. J., and U. J. McMahan (1976) The shapes of sensory and motor neurons and the distribution of their synapses in ganglia of the leech: A study using intracellular injection of horseradish peroxidase. Proc. R. Soc. Lond. (Biol.) 194: 481499.

Nicholls, J. G., and D. A. Baylor (1968) Specific modalities and receptive fields of sensory neurons in the CNS of the leech. J. Neurophysiol. 31: 740-756.

Pruss, R. M., R. Mirsky, and M. C. Raff (1981) All classes of intermediate filaments share a common antigenic determinant defined by a monoclonal antibody. Cell 27: 419-428.

Sternberger, L., K. W. Harwell, and N. H. Sternberger (1982) Neurotypy: Regional individuality in rat brain detected by monoclonal antibodies. Proc. Natl. Acad. Sci. U. S. A., 79: 1326-1330.

Stewart, W. W. (1978) Intracellular marking of neurons with a highly fluorescent naphthalimide dye. Cell 14: 741-759.

Stewart, W. W. (1981) Lucifer dyes-highly fluorescent dyes for biological tracing. Nature 292: 17-21.

Stuart, A. E. (1970) Physiological and morphological properties of motoneurons in the central nervous system of the leech. J. Physiol. (Lond.) 209: 627-646.

Trisler, J. D., M. D. Schneider, and M. Nirenberg (1981) A topographic gradient of molecules in retina can be used to identify neuron position. Proc. Natl. Acad. Sci. U. S. A. 78: 2145.

Weisblat, D. A., G. Harper, G. S. Stent, and R. T. Sawyer (1980) Embryonic cell lineages in the nervous system of the glossiphoniid leech Helobdella triserialis. Dev. Biol. 76: 58-78.

Zipser, B. (1979a) Identifiable neurons controlling penile eversion in the leech. J. Neurophysiol. 42: 455-464.

Zipser, B. (1979b) Voltage-modulated membrane resistance in coupled leech neurons. J. Neurophysiol. 42:465-475.

Zipser, B., and R. McKay (1981) Monoclonal antibodies distinguish identifiable neurons in the leech. Nature 289: 549-554. 